\title{
sciendo
}

DOI: $10.2478 /$ abcsj-2019-0004

American, British and Canadian Studies, Volume 32, June 2019

\section{A Portrait of the Mehmandar: Accompanying Hajji Baba, of Ispahan, to England}

\author{
ALINA PELEA \\ Babeș-Bolyai University, Cluj-Napoca, Romania
}

\begin{abstract}
There are few professions and professionals to be constantly perceived as ambivalent. But for interpreting and interpreters, this seems to be the norm, rather than the exception. On the one hand, there has always been a sense of fascination for these extraordinary people who speak so many languages and have such a wide knowledge of the world. On the other, they have inspired reluctance, distrust or even fear. While literary works sometimes reflect one or the other perception, James Justinian Morier's The Adventures of Hajji Baba, of Ispahan, in England (1828) reflects both and provides us with an insight into the nature and circumstances of the situation. By following the attitude towards the mehmandar throughout the novel, the present paper considers a set of memes that seem to be still valid today. The reasons this is so relate to features inherent in the profession, the privilege of understanding both sides 'of the coin', the power tamper with information, the risk of misunderstanding, etc.
\end{abstract}

Keywords: mehmandar; interpreter; James Morier; Hajj Baba; ambivalence; pure customer; fictitious translation

\section{James Justinian Morier and His Persian Experience}

James Justinian Morier (1780-1849) was a British diplomat who worked in Persia from 1808 to 1809 and 1810-1814 (Amanat). The experience and knowledge that he acquired during these years inspired him to write two travel books, A Journey through Iran, Armenia and Asia Minor to Constantinople in the Years 1808 and 1809 (1812) and A Second Journey through Iran to Constantinople between the Years 1810 and 1816 (1818), as well as several novels among which The Adventures of Hajji Baba of Ispahan (1824) and The Adventures of Hajji Baba, of Ispahan, in England 
(1828). The first novel was well received and still enjoys a certain success: it was translated into French and German as early as 1824, and it has been constantly reprinted since (the latest edition we could identify was from 2015 (CreateSpace Independent Publishing Platform). It was made into a movie in 1954 and a humanitarian operation by the US Air Force was named after the main character in 1952 (Boyne). In Encyclopaedia Iranica, Abbas Amanat calls it "the most popular Oriental novel in the English language and a highly influential stereotype of the socalled 'Persian national character in modern times'." The novel was even translated into Persian - the alleged original language of the diary - and published in 1905. According to the online Encyclopedia Britannica, this translation "led to the development of the modern Persian novel of social criticism". This translation had a certain impact on the Persian society of the time (at least while it was not known that it was not an original): "We might find that distinction in the reported first reception of Hajji Baba as a fully Persian picaresque, when it was seen as witty and perceptive selfreflection, then becoming unacceptable as soon as it was viewed in a referential light, as having been transferred from abroad" (HaddadianMoghaddam and Pym). Nevertheless, Amanat stresses that the novel was somehow popular for the 'wrong' reasons, as "[i]n the decades following the publication of Hajji Baba, one can discern a correlation between its increasing popularity and the decline of Persia's image in the West, especially after the defeat in war with Russia in 1827" (HaddadianMoghaddam and Pym).

The sequel had a somehow different fate:

This is a reprint of a book published in 1828, which never met appreciation and is likely to be appreciated less now than it was at its first appearance nearly a century ago. Morier's first book, The Adventures of Hajji Baba of Ispahan, has deservedly become a classic. [...] The attempt to transplant the imaginary Hajji Baba from his native Persia to the England of the pre-Victorian period [...] has been much less successful and infinitely less amusing. (Dewhurst 785)

Whether or not the novel is valuable from an aesthetic and literary point of view, it is interesting for us in this context because the visit of the Persian delegation to London involves the presence of interpreters whose 
portraits reflect a certain perception of the profession. Given Morier's experience as a diplomat, the image he draws and the adventures he recounts are likely to be inspired by his real life experiences. To what extent the views that he expresses are his own or indeed those of an imaginary character, it is sometimes difficult to say. Yet, comparing them with those of other authors and characters could shed significant light on the elements making up the image of the interpreter in the eyes of his customers. We fully agree with Karlheinz Spitzl in what the value of fiction as an indicator of reality is concerned:

In an act of touching (not taking), fiction evokes rather than denotes. For this reason, it is a particular useful resource in the exploration of feelings that arise in translated or interpreted interaction. Emotions, such as audacity, passion, desire, empathy, be/ longing, shame, anger, fear, anxiety ... or subconscious acts [...] can all have agency with regard to performance and outcome (meaning). (365)

\section{Hajji Baba, of Ispahan, in England - a "Translated Diary"}

Hajji Baba, of Ispahan, in England also takes the form of a diary supposedly translated from Persian into English, therefore Morier acknowledges from the start a subjective standpoint and, as we can assume, feels free to express his personal opinions. After all, he stands at two removes, doubly protected, by the imaginary identity of the author and by the translator status, a safeguard he might have been forced to find if indeed, the fictitious translation of a diary served him as vengeance for not having been able to translate a real Persian's texts about England:

One can therefore accept that there is a grain of truth in Morier's claim that he is a 'humble translator' of a genuine "Asiatic" life story. It is likely that Morier's frustrated attempts to obtain a copy of the Hayrat-nāma for translation led him to invent his own Hajji Baba instead, as a grotesque caricature of the Ilči, no doubt with a degree of vengeance. [...] Moreover, Hajji Baba should be read in the context of Morier's deeper frustration with the Persian government's refusal in 1822-23 to accept him as the British envoy to the Persian court, after having to wait several years for a diplomatic posting. ${ }^{1}$ (Amanat) 
One more reason to assume real opinions based on real-life experiences are expressed.

\section{The mehmandar: from friend to foe?}

The evolution of the mehmandar in the eyes of Hajji Baba and the Persian delegation confirms, in our opinion, the ambivalence that Klaus Kaindl points to:

\footnotetext{
The reason why it is translators and interpreters who are used in literature to embody existential conflicts and contradictions may also be rooted in the ambivalent characteristics ascribed to them and their work in the course of history: They are invisible and ubiquitous, subordinate and powerful, faithful and dubious, oppressed and uncontrollable, and they can enable or prevent communication - in other words, they are changeable, oscillating beings that are hard to grasp because they are constantly in motion and have so many layers to them. (9)
}

In what follows, we will look at the details of this ambivalence in the case of Hajji Baba, of Ispahan, in England in order to highlight its particular circumstances and grasp the evolving attitude towards this professional role. The role of mehmandar or interpreter, it is important to stress from the outset, is played by at least three individuals in the novel, all identified simply by their profession (which in itself indicative of the customer's perception: the person's qualities are shadowed by the professional's performance).

At this point, a terminological distinction needs to be made. While the role of the interpreter designated as such is that of a "mere" supplier of linguistic services, the mehmandar - like the one Hajji Baba regularly evokes in his diary - is an interpreter, a guide, a cultural mediator and a protocol officer. According to the Merriam-Webster, s/he is "an official in India, Persia, or Afghanistan appointed to escort an ambassador or traveler", , but, as the reader discovers in Hajji Baba, this position largely involved tasks still associated today with interpreting: actual interpretation from one language to another and explication of those cultural aspects that risk causing misunderstanding. His work inevitably involves interpretation to the extent to which the question arises whether he is actually a diplomat 
providing also interpreting services or rather an interpreter providing diplomatic services. Furthermore early on in the novel, Morier talks of a "young infidel [...] who was appointed to attend the Persian embassy to England to act as an interpreter, and, when the occasion required, as mehmandar" (24). Hence, our decision to assimilate the mehmandar to the interpreter, a decision supported by the decision of the French translator to alternate mehmandar and interprète as equivalents of the English mehmandar (see, for example, Morier 95).

The need of an interpreter seems to be acknowledged by the fact that he is a member of the delegation from the very beginning of the journey. Yet, his 'customers' have unrealistic expectations of him:

The young infidel before alluded to, who had accompanied the English ambassador to Persia, and who knew but just enough our language to misunderstand all that we said, was to proceed in the train of Mirza Firouz, and when we reached his own territory was to act as an interpreter; for he calculated that during the journey he would be so much under the necessity of learning Persian, that before we reached England we should be able perfectly to understand each other." (29)

Thus, it is maybe not all that surprising that, once the delegation arrives in England a mehmandar replaces the interpreter. It might have become clear that in the meantime the latter only offered a relative (or should we say dangerous?) level of linguistic knowledge and, undoubtedly, the mission required anyway more than a mere transfer of words from one language to another:

A mehmandar was also appointed, whose duty was to collect and distribute the daily allowance of provisions granted for the use of the embassy, according to the established usages of the empire. The young infidel who had accompanied us, and who now made himself tolerably well understood in our language, left us [...] and shortly after preceded us $[\ldots]$ in order to prepare a ship to conduct us to England. (38)

A mehmandar, as the previous definitions indicated, has a much broader role than an interpreter. One very relevant passage in this respect the episode of the first Persian-English interaction. Hajji Baba, a very sincere pure customer, recounts it in detail and, after providing a thorough 
description of the long and very elaborated speech given by the Persian ambassador, he focuses on the shocking rendition of the mehmandar:

[...] The mehmandar having, as it appeared to us, in six words interpreted this, all that the ambassador got in answer was, 'Oh!' How what he had to say could have been thrown into so short a word, we have still to learn. The ambassador waited for some time to an answer to his speech and was curling up his moustache, and smoothing his beard, in the hopes of an equivalent return of compliment, when the governor broke a long silence by remarking that it was a fine day; not meaning, as we should have said in Persia, that the sun shone because of the joyful event of the ambassador's arrival, but that it really was fine, and did not rain. We all looked at each other, and as soon as he had taken his leave, and when the mehmandar had also left us, we gave full vent to our feelings. 'Did you ever see such an ass?!' exclaimed one. 'A governor indeed! A Persian dog would make a better', said another. 'Praise be to God, said a third, 'where are the Franks ${ }^{4}$, and where are the Persians? A Persian camel-driver would speak better than this infidel'. (77-78)

Fortunately, the Persian delegation decides not to judge the entire English people based on the impression made by this first official and the newly appointed mehmandar is regarded with confidence, even admiration; and a little envy. This overall benevolent attitude is largely explained by the qualities still considered today essential in interpreters: a thorough linguistic knowledge combined with impressive knowledge of the customers' culture:

His good humour was increased by the arrival of a Franck of consequence, who was announced to him as the mehmandar appointed to attend him, during his stay in England, by the English shah, and who talked our language with so much facility and purity, that everything seemed now to promise fair for making progress in the object of our mission. He not only spoke Persian, but he wrote it with as much elegance as one of our best moonshis; he had read all our best authors; had Hafiz and Saadi at his fingers' end; and, to say the truth, we soon found out that the ambassador would have been happy had he not been quite so learned, since he was every now and then obliged to chew the cud of shame, and swallow the bitter draught of ignorance. (100)

Not surprisingly, the mehmandar is a trusted and invaluable source of information. For example, when protests occur in London, the Persians 
immediately and quite naturally turn to the mehmandar for an explanation of the disturbing events.

"[...] Before we go further, I who am the least of your servants, would recommend you to enquire more narrowly into the state of this country, and the stability of the present shah's throne."

"You do not speak ill," said the ambassador: "where is the mehmandar? Let us ask him, what does all this mean? Whatever he says you will duly write down, and by the next letters sent to the shah's gate at Tehran, we will detail all that has happened, and give in a few words a full account of the government of this country." [...]

At this moment entered the mehmandar: and the shower of questions which the ambassador immediately poured over him so astonished him, that he looked liked [sic] one drenched, whose breathing and power of utterance were taken from him. (222-223)

This beautiful portrait of the perfect interpreter as seen by his/her customer could still be an inspiration for anyone wishing to join the profession. It reflects, in very concrete terms, one of the extremes in the attitude people tend to have towards interpreters: admiration for their knowledge of the foreign language and culture (the proficiency of which is assumed to be only matched by that of native speakers) and for their background knowledge. This passage thus reminds us of an episode recounted by Epaminonda Stamatiades in his volume of biographies of Grand Dragomans of the Porte. The similarity between the two scenes, one fictional, one non-fictional, suggests, in our view, that Morier's opinion are likely to reflect real situations and attitudes. Impressed by Panagiotis Nikousios's knowledge of languages and sciences, by his diplomatic skills and courage, the Vizier and his court unanimously regret that such a genius was not Turk (21)... Though brilliant, the mehmandarhimself, only human, after all - is rarely puzzled and rarely finds himself in difficult situations. During the first days of the visit, a question pertaining to cultural differences takes him - who is more aware than anyone else of the existing cultural differences - by surprise:

"How should we know that?" said the cook; "how are we to distinguish between your lords and your doctors?" 
This puzzled the mehmandar; for truly everybody seemed to be on an equality in this strange country. To judge of people by their dress was impossible. (95)

Later on, taken aback by the behaviour of one of his own people, he finds nevertheless the right advice to give to this employer:

The mehmandar was as much puzzled as ourselves how to account for what had happened. He warned the ambassador against receiving into his house persons who were not properly introduced to him; remarking that London was not like Ispahan, where every individual was more or less known [...]. (179)

The mehmandar turns out to be indispensable for the Persian delegation, who are always taken aback by the weird Franck habits, clothes, speech, etc., and whose level of English is still low. In situations involving strict protocol, in everyday circumstances which Orientals find puzzling (95), whenever there is incomprehension, doubt or even fear of having done something wrong, the mehmandar comes to rescue. And, for quite some time, his knowledge, good intentions and phrasing are unquestioned. Filled with admiration and ignorant of so many in the new country, his customers often look up to him as the source of all the answers they need:

This apprehension [that the Franks might not have appreciated their way of starting a negotiation] began visibly to work upon Mirza Firouz. He inquired at every moment whether the mehmandar had returned; and by way of consoling himself, he walked about the house inquiring of every man he saw 'After all, did I not say well? (114)

The role the mehmandar comes to play can also be explained by his concrete diplomatic skills. He understands the two parties both linguistically and culturally, holds an overview of the situation and does not lose sight of the objectives. Thus, he goes as far as to anticipate difficulties and, in doing so, he relieves his customer's burden. The latter is simply presented with the results and made even more aware of how important the mehmandar is (though an infidel, as Hajji Baba constantly reminds us): 
To this the mehmandar answered, 'May your friendship never diminish. I have made known your wishes to the vizier for foreign affairs'. did he say?"

"Well", said the ambassador, all of a sudden excited, "and what

"He said", returned the infidel, "that there would be no difficulty in giving you a public audience. We have plenty of coaches, abundance of fine clothes, and fine things, and you shall go before the king, accompanied in any manner you choose."

"Wonderful!" exclaimed the ambassador, "wonderful! I do not understand you English at all! You make no difficulties. You leave no room for negotiation."

"Not upon trifles", returned the mehmandar. (114-115)

To avoid offending the foreign guests, the mehmandar, a natural born diplomat goes on to say, in response to Mirza Firouz's surprise:

"The nations of Europe were fools enough in the past," said the mehmandar, "to make matters of etiquette affairs of state, and they used to lose intrinsic advantages in pursuing these ideal ones; but they are become wiser; we look upon etiquette now as child's play. However, in consideration of your being Persian, and knowing no better, we do not hesitate in giving you as much as you please". (115)

The answer is not entirely pleasing, but at least major damage has been avoided. In this climate of trust, it is not surprising - and not uncommon in so many real life situations, after all - that the mehmandar is sometimes not even mentioned when everything goes well (see, for example, 152-3). Actually, to this very day it is believed the best compliment that can be paid to an interpreter is for him/her to go unnoticed.

As the visit progresses, the members of the Persian delegation learn more and more about England, understand English better and gain a certain autonomy. All that impacts on the perception of the mehmandar, who is no longer the only one who knows. He does maintain his upper hand however, given the time it takes to become so fluent in a language and a good mediator, yet his customers become suspicious of his services and impartiality. They no longer trust him blindly, for they become aware of all the power linguistic knowledge involves. An incident (which took place, paradoxically, because the interpreter was not involved) is one of 
the hints that accumulate to indicate that mastering the language is the first step towards mastering the minds:

This was a disagreeable ending to the successful doings of the morning, and set us all exclaiming 'La illaha, illallah!' for the rest of the day. We could only account for it by the following circumstances: A Franck, having been appointed to wait upon the servants by way of interpreter, had taken advantage of his knowledge of the Turkish language, to talk to them of the freedom enjoyed by all ranks of people in England; he informed them that every man was under the protection of the laws - that no man had the right of bastiona doing another. (121)

If, at the beginning, the other side was blamed for whatever went wrong, progressively, the suspicion falls on the mehmandar, whose subversive potential becomes a source of doubt as to his trustworthiness. In the following scene, there is only surprise, there is no resentment:

The mehmandar entered into long explanations upon this subject, which we could in no wise understand; and however he and the governor might seem to look upon their king's government as more firmly fixed by this even [protests of the Opposition], still we doubted whether there was wisdom in proceeding on an embassy to a country full of internal broils [...]. (57)

And his knowledge of the English society does not always convince the Persian delegation. Once the mehmandar is gone, his trustworthiness is seriously questioned, as the explanation seemed too far-fetched for the Orientals:

The mehmandar was no sooner gone than we began to give vent to our astonishment and incredulity:

"That man," said Mohamed Beg, "is a liar; he must be a liar: who can believe his stories? Feth Ali Khan, our king of poets himself, could never have invented such lies, if he had even tried them in his dream."

"These Franks, it is true," said I, "differ totally from ourselves: but, after all, there are things credible, and things incredible. [...] but whose imagination ever compassed the sum he mentions? " (225-226)

Before looking at specific ways in which this mistrust gains the Persians' minds, it has to be said that this attitude alternates with the 
acknowledgement that the mehmandar is needed. The awareness of his possibility to manipulate comes progressively. Despite the anger and the doubt, he is still relied upon in delicate or difficult situations, doubt sometimes arising because the information is shocking in itself:

But all our dreams vanished when the mehmandar told us, that on the next day, shortly after morning prayer, a coach was to conduct us to the foot of the throne. He warned us to be ready at a particular hour; for he assured us, that which we would scarcely believe, that such was the despotic nature of the men who drove those coaches, that they would not wait any man's pleasure, not even for their own shah, did he happen to require the delay of an hour or two. And the fact proved his words true [...]. (92; see also 167, 225-226)

Persians also become aware of the limitations imposed by the transfer from one language to another, when their efforts to seduce a beautiful lady with verses from Hafiz. Nota bene, this is not directly imputed to the mehmandar's skills or lack of skills.

"But, indeed," said the ambassador, "I did say plenty of enraptured things to her in verse! but who could understand me? ' $t$ is true, the mehmandar endeavoured to interpret my expressions, but instead of softening her heart, she, her mother, and those around us, only laughed, and asked me to write down what I had said." (163)

It is thus understandable that Hajji Baba is motivated to study English more so as not to have to rely on another person's services:

I began now to make myself tolerably well understood in the English language. ' $\mathrm{T}$ is true that I was very often incomprehensible; and many words which I had picked up from my friends on board ship I soon found were none of the most refined, and did not pass at court. The ambassador, too, ventured in great measure to free himself from the tutorage of the mehmandar, and to speak for himself. He had more opportunities than I of exercising his knowledge, and occasionally into difficulties by too great confidence in his own powers. (168)

And the dictionary turns out at one point to be more trustworthy than the linguist: 
"For the sake of Ali," said he, "bring me immediately that vocabulary of English words which the foozool, that over officious person, on board the last ship taught us. I am in the greatest fear that I have made some terrible mistake, and that the designing wretch has purposely misled us." (168-9)

When the lack of trust reaches unprecedented levels, Hajji Baba prefers his approximate English to the services of the mehmandar. Proud of having written a letter by himself, he gets to the conclusion that the mehmandar is to blame for all the misunderstandings and decides to tell his master about this. The words he uses are harsh and nothing the mehmandar had done right is not remembered anymore:

Having despatched this letter to the father Hogg, I felt more at my ease; but I determined to let the ambassador know, that if we had acquired a bad name in this foreign country, it was not through our faults, but through the words of that ill-conditioned infidel, the mehmandar. Evidently our chief was now becoming very impatient at the slow mode of transacting business among the Franks, for the object of his mission had not yet been fulfilled; and as the mehmandar came every day with a new story and a fresh excuse, each of which proved to be as false as the other, it would not be difficult to prove the baseness of his character. Why then should I not scrape my heart clean, and expose its scouring and the conduct of this infidel at one and the same time? (217-218)

Yet, the way to linguistic autonomy is long and the mehmandar's assistance is still needed, as illustrated in Chapter XLVII, where Hajji Baba's reluctance and mistrust is countered by the ambassador's constant request of information and advice from the mehmandar. Is it that the diplomat shows less his actual feelings for practical reasons, while Hajji Baba risks nothing by being perfectly sincere in his diary? Is it that the same character, in the same context, can be looked at in such different ways? In our opinion, this is only another face of the interpreter's ambivalence: depending on one's more or less subjective stance, the professional will be seen as indispensable help or potential traitor.

The mehmandar loses face for very objective reasons, when the above mentioned letter he wrote gets into the hands of Hajji Baba, now proficient enough to understand the real feelings of the Englishman. His views on Persians are very harshly expressed and leave no room for interpretation. We will quote the first lines, which are illustrative for the 
entire one-page letter: "[...] I can only say, that I would rather tie a milestone about a sister's neck, and throw her into the sea, than marry her to a Persian." (246) Can someone who has devoted long years to a language and culture be critical to such extent? Could any diplomat be as imprudent as this poor mehmandar? It's quite hard to believe. If there is one unlikely episode in the novel, it is most certainly this one... which certainly gives a funny twist to the entire story. The mehmandar's ambivalent nature - or we should maybe say... betrayal - gives new impetus to the narration.

The lack of professionalism has dire consequences. From there onwards, Hajji Baba will only try to confound the mehmandar, firstly by writing a letter to the same Mr Hogg who had received the previous one. A revenge letter:

My dear Friend,

Pon my honour, mehmandar one bad man. What for he want to throw Miss Beassy in sea, sir? What for he write lies, sir? [...] Why he tell lies? [...] What he want more, sir? I very angry.

Then he say other great lies. He say Persian women bad. Where he see Persian women, sir? He not known one, sir. The how say whether she be good or bad. (247)

The readers know Hajji Baba himself had been far from honest... Hence, the conclusion to draw from this incident is that, as always, the interpreter is a position which makes him an easy scapegoat. It must have happened many times before Morier's story and, most certainly, it will happen again.

Interestingly enough, once the mehmandar - still in office, still indispensable despite the letter incident - is under scrutiny, the cultural information he provides is even less easily accepted. While it used to be a sign of how strange the English are, now this information is regarded as an exaggeration by the mehmandar. A quite illustrative example is the following passage, in which Hajji Baba is convinced he has found a contradiction: if, for the English, one day is not necessarily more fortunate than any other, how come it was so difficult to negotiate a date for a ziafet the ambassador wanted to organize for the heir to the British crown?! 
[...] one of the great difficulties was to fix upon a proper day. This we thought extraordinary, because the mehmandar had taught us to believe all days were alike in the eyes of his countrymen; that one was not more fortunate than another. His lies became hourly more palpable. (218)

Even silence is interpreted: "You do not say ill, Hajji," said my chief, much pleased with my suggestion, whilst the mehmandar held his tongue in peace, like a man who could say much but would not." (263)

In a nutshell, the mehmandar is by no means an innocuous character. He might be "just" an official representative, "just" an inbetween, he is not invisible and his actions (actually, words more often than not) have an impact. He is under suspicion because he is like one of the Others, but also because he knows both languages and has a profound understanding of how the world works.

\section{Conclusion}

What would a real Hajji Baba answer to the question "What is your opinion about mehmandars?" Most likely, he would give an apparently contradictory answer, using words such as "brilliant", "skillful", "knowledgeable" alongside "spy", "traitor", "arrogant". He would thus reflect what seems to be a prevalent perspective on interpreters.

Indeed, Hajji Baba's fictitious diary is an anticipated confirmation of the conclusion Kaindl draws on interpreters and translators as literary characters on the basis of almost two centuries of fictional works:

The reason why it is translators and interpreters who are used in literature to embody existential conflicts and contradictions may also be rooted in the ambivalent characteristics ascribed to them and their work in the course of history: They are invisible and ubiquitous, subordinate and powerful, faithful and dubious, oppressed and uncontrollable, and they can enable or prevent communication - in other words, they are changeable, oscillating beings that are hard to grasp because they are constantly in motion and have so many layers to them. (9)

Is this to say that there are certain memes meant to survive whatever progress is made in terms of professionalization? Are interpreters and translators subject to an inevitable, perennial ambivalent attitude on the 
part of their customers, indeed audiences? Given the basic, unchangeable characteristics of the profession, most likely the answer to both questions is "yes". Nevertheless, a few nuances should be highlighted to make justice to all the efforts made in the last century: regular professional training results in less problematic situations giving rise to suspicion, the existence of ethical codes and professional associations offers guarantees Hajji Baba could not even dream of, and, last but not least, the clear definition of these professions makes the necessary delimitations for protecting against ambiguous (and, hence, dangerous) roles.

If any change is to be expected, it is one of scale and frequency. Considering the predicament of interpreters in war zones today and that of the public service interpreter in many parts of the world, we tend to think that efforts are still to be made for reducing this prevalent attitude towards this profession. Hajji Baba's voice, be it "translated" by James Morier, is in this respect of continuing relevance, acting as a 'bell ringer'.

\section{Notes:}

1 "In response Morier only adds insult to injury by including, in the introduction of Hajji Baba of Ispahan in England, a letter in broken English which was supposedly written by the Persian envoy to complain about Morier's abuse of himself and his countrymen in the book: 'You call me Mirza Firouz, I know very well, and say I talk great deal nonsense. When I talk nonsense? Oh, you think yourself very clever man; but this Hajji Baba very foolish business' (Morier, 1942, p. 22)" (Amanat).

${ }^{2}$ According to Wiktionary "the mehmandar is an official courier appointed to escort an important traveller in Persian-speaking countries and the Indian subcontinent".

${ }^{3}$ The same attitude towards languages (and, implicitly, translators) is visible in the mission Hajji Baba himself is assigned: "'Go, do good service; labour hard to make the shah's face white in a foreign land. Open your understanding and learn things useful. The shah expects you to understand all the languages of the Franks at your return, in order that you may be able to able translate all their books, and let us know under what star the infidel of these unknown regions draw the breath of life. Go, and having done this, the condescending looks of the king of kings await thee"" (57).

${ }^{4}$ This is how the Persian delegation designates the English.

${ }^{5}$ It might be interesting to notice that sometimes the mehmandar explicitly places himself on the English side, which indicates that in his view and also officially, he was more of a diplomat than "just" an interpreter. 


\section{Works Cited}

Amanat, Abbas. "Hajji Baba of Ispahan." Encyclopcedia Iranica XI.6. (2003): 561-568. Web. 15 Feb. 2019.

Boyne, Walter J. “The Pilgrim Airlift.” Air Force Magazine Mar. 2007. Web. 15 Feb. 2019.

Dewhurst, R. P. "The Adventures of Hajji Baba of Ispahan in England. By James Morier. London: Oxford University Press, 1925." Journal of the Royal Asiatic Society 57.4 (1925): 785 . Web. 15 Feb. 2019.

Kaindl, Klaus. "Going Fictional! Translators and Interpreters in Literature and Film: An Introduction." Transfiction: Research into the Realities of Translation Fiction. Ed. Klaus Kaindl and Karlheinz Spitzl. Amsterdam: Benjamins, 2014. 1-26.

Morier, James Justinian. Les Aventures de Hadji Baba en Angleterre. Texte français pas Robert Pépin. Paris: Phébus, 1986.

---. The Adventures of Hajji Baba, of Ispahan, in England: Revised, Corrected, and Illustrated with Notes, and an Appendix by the Author. Paris: Baudry's European Library, 1835. Web. 15 Feb. 2019.

Haddadian-Moghaddam, Esmaeil, and Anthony Pym. "Voice in the Persian Hajji Baba." La traduction des voix intra-textuelles/ Intratextual Voices in Translation. Ed. Kristiina Taivalkoski-Shilov and Myriam Suchet. Montréal: Éditions québécoises de l'oeuvre, collection Vita Traductiva, 2013. Web. 15 Feb. 2019.

Spitzl, Karlheinz. "Fiction as a Catalyst: Some Afterthoughts." Transfiction: Research into the Realities of Translation Fiction. Ed. Klaus Kaindl and Karlheinz Spitzl. Amsterdam: Benjamins, 2014. 363-368.

Stamatiade, E. I. Biografiile marilor dragomani (interpreți) greci din Imperiul Otoman. Trans. Constantin Erbiceanu. Bucuresci: Tipo-litografia « Cărților Bisericescî », 1897. Web. 15 Feb. 2019. 